
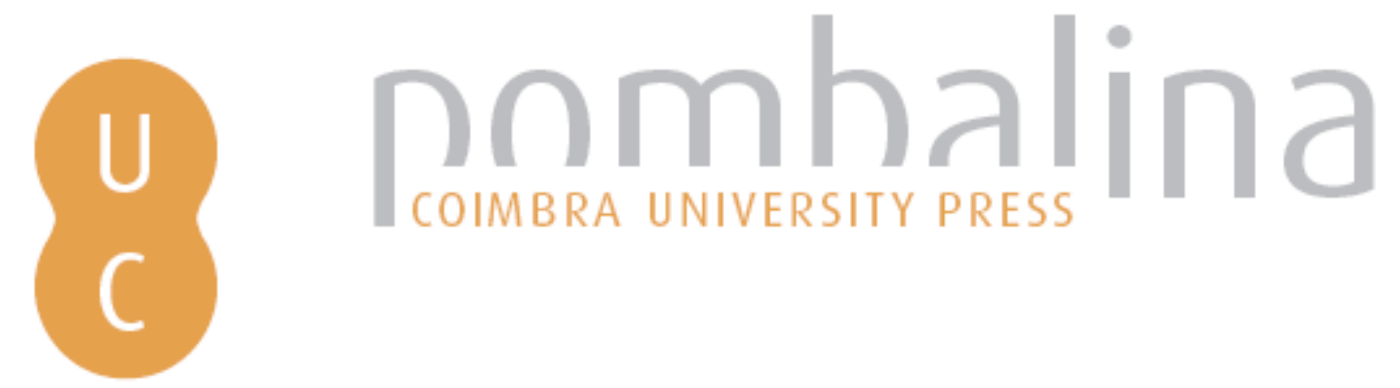

\title{
A tomografia por emissão de positrões na investigação da relação comportamento/função cerebral
}

\author{
Autor(es): $\quad$ Lima, João José Pedroso de \\ Publicado por: Imprensa da Universidade de Coimbra; Gradiva \\ URL \\ persistente: URI:http://hdl.handle.net/10316.2/32685 \\ DOI: $\quad$ DOI:http://dx.doi.org/10.14195/978-989-26-0389-6_13 \\ Accessed : $\quad$ 26-Apr-2023 10:43:17
}

A navegação consulta e descarregamento dos títulos inseridos nas Bibliotecas Digitais UC Digitalis, UC Pombalina e UC Impactum, pressupõem a aceitação plena e sem reservas dos Termos e Condições de Uso destas Bibliotecas Digitais, disponíveis em https://digitalis.uc.pt/pt-pt/termos.

Conforme exposto nos referidos Termos e Condições de Uso, o descarregamento de títulos de acesso restrito requer uma licença válida de autorização devendo o utilizador aceder ao(s) documento(s) a partir de um endereço de IP da instituição detentora da supramencionada licença.

Ao utilizador é apenas permitido o descarregamento para uso pessoal, pelo que o emprego do(s) título(s) descarregado(s) para outro fim, designadamente comercial, carece de autorização do respetivo autor ou editor da obra.

Na medida em que todas as obras da UC Digitalis se encontram protegidas pelo Código do Direito de Autor e Direitos Conexos e demais legislação aplicável, toda a cópia, parcial ou total, deste documento, nos casos em que é legalmente admitida, deverá conter ou fazer-se acompanhar por este aviso.

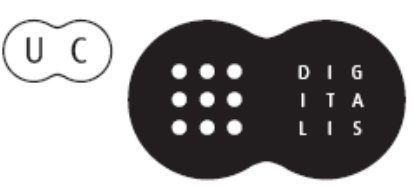


C I E N C I A I B E R T A

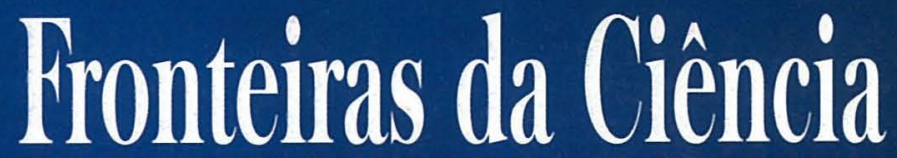

Desenvolvimentos Recentes - Desafios Futuros

RUI FAUSTO • CARLOS FIOLHAIS • JOÃO FILPE QUURRÓ

Coordenadores

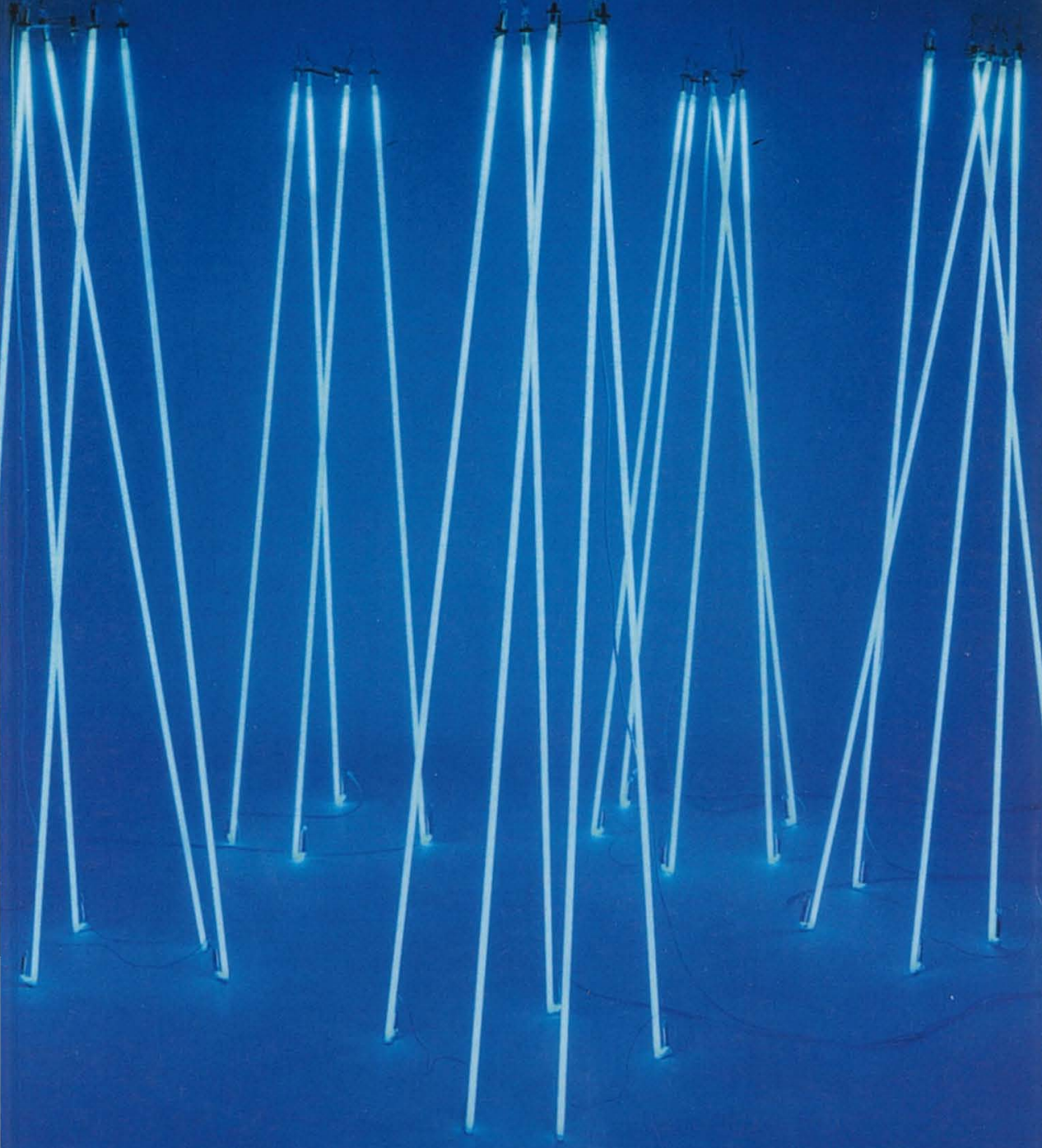

gradiva - Imprensa da Universidade de Coimbra 
(Página deixada propositadamente em branco) 


\section{RUI FAUSTO, CARLOS FIOLHAIS JOÃO FILIPE QUEIRÓ \\ Coordenadores}
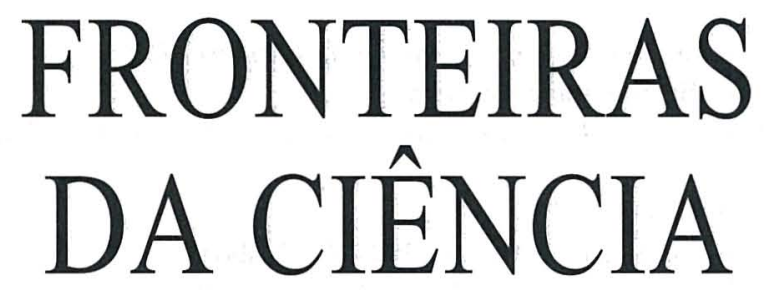

Desenvolvimentos Recentes Desafios Futuros 
(C) Gradiva - Publicações, L. da / Imprensa da Universidade de Coimbra, 2003 Coordenação editorial: Rui Fausto, Carlos Fiolhais e João Filipe Queiró Tradução: Jean Burrows, Vivien Burrows, Rui Fausto, Carlos Fiolhais e João Filipe Queiró

Revisão do texto: Isabel Pedrome

Capa: António Barros [Imprensa da Universidade. Coimbra], sobre imagem de «Águas Vivas», escultura de Silvestre Pestana, 2001

Foto: António Alves; Infografia: ESTÍMULUS [design]; Cortesia: Galeria Alvarez-Arte Contemporânea

Paginação: António Resende e Paula Isabel Jorge

Impressão e acabamento: G.C. - Gráfica de Coimbra, L. ${ }^{d a}$

Reservados os direitos para Portugal por:

Gradiva - Publicações, L. ${ }^{\text {da }}$ e Imprensa da Universidade de Coimbra

Gradiva - Publicações, L.da

Rua Almeida e Sousa, 21, r/c, esq.•1399-041 Lisboa

Telefs. $213974067 / 8 \cdot 213971357 \cdot 213953470$

Fax $213953471 \cdot$ Email: gradiva@ip.pt

URL: http://www.gradiva.pt

Imprensa da Universidade de Coimbra

Rua Antero de Quental, 195 • 3000-033 Coimbra

Telefs. 351239853110

Fax 3512398531 19・e-mail: fjrpress@ci.uc.pt

URL: http://www.imp.uc.pt

ISBN: 972-662-923-3

1." edição: Agosto de 2003

Depósito legal n. ${ }^{\circ} 199$ 463/2003 
João José Pedroso de Lima

Faculdade de Medicina

Universidade de Coimbra

\section{A tomografia por emissão de positrões na investigação da relação comportamento / função cerebral}

O título da comunicação de Alexandre Quintanilha, «Uma visão biofísica do stress nos sistemas vivos», é sem dúvida muito abrangente, visto incluir processos que vão do celular ao social.

Os agentes de stress desencadeiam perturbações complexas a nível fisiológico, com repercussão neurológica, endócrina, auto-regulatória e comportamental. Por exemplo, o conjunto das alterações físico-químicas associadas a estas reacções pode induzir aumentos da frequência e débito cardíacos, elevação da pressão sanguínea e redistribuição da volémia. Igualmente, e ainda no conjunto das alterações, são observados valores elevados nas catecolaminas plasmáticas, cortisol e opiácios endógenos.

Vive-se, presentemente, uma fase de expectativa em medicina com o desenvolvimento de métodos de análise da bioquímica humana no vivo com o PET (Positron Emission Tomography), a RMN (Ressonância Magnética Nuclear) funcional e o SPECT (Single Photon Emission Computorized Tomography). Estes estudos são parte de um conjunto que se espera poder melhorar o conhecimento das relações entre a bioquímica do cérebro, a personalidade e o comportamento humanos. Devido sobretudo a condicionalismos técnicos, a aproximação global que tem sido efectuada é tomográfica. As máquinas rodam em torno dos pacientes, 
adquirindo informações de diversos tipos, como por exemplo circulação sanguínea, concentração protónica, actividade química e alterações metabólicas de substâncias específicas, reconstruindo, a partir daí, mapeamentos da propriedade adquirida, em tomogramas (cortes) do paciente.

A PET utiliza radionuclidos artificiais de baixo peso molecular, emissores puros de positrões, para fornecer imagens paramétricas de funções metabólicas. A informação veiculada pela PET é essencialmente metabólica e difere da fornecida pela TAC ou RMN, que são informações sobretudo de natureza estrutural. A PET permite detectar alterações exclusivamente funcionais e é mais sensível do que as segundas na detecção precoce de processos patológicos, visto, sistematicamente, as perturbações metabólicas precederem as alterações estruturais na evolução destes processos.

A tomografia de emissão de positrões (PET) utiliza a aniquilação de positrões, emitidos por radioisótopos que se ligam a fármacos a fim de obter imagens quantitativas de funções regionais do cérebro e outros órgãos. A circulação sanguínea cerebral, a utilização do oxigénio, o metabolismo da glucose, vários sistemas neurotransmissores [dopamina, opiácios, serotonina, acetilcolina (muscarínica), ácido g-aminobutírico e glutamato] e numerosos processos farmacológicos foram e estão a ser investigados pela PET. Em alguns centros de investigação, o interesse centra-se no estudo das modificações neuroquímicas associadas a estados de vigília. Isto tem particular relevância para a activação neuronal em algumas situações patológicas, onde a interligação entre a resposta da circulação cerebral e a neuroquímica pode estar alterada, o que tem considerável interesse científico. Com estas metodologias, surgiram novos conhecimentos na área das interrelações entre as funções sensorial, motora e cognitiva, assim como da fisiopatologia das doenças cerebrais.

A PET fornece, de forma não invasiva, informações funcionais a nível cerebral, uma possibilidade onde os outros métodos não são competitivos. De facto, a sensibilidade dos estudos com traçadores no vivo com a PET é ordens de grandeza maior que a da RMN funcional e também substancialmente superior às modalidades mais avançadas da SPECT.

Apesar de menos sensível, a RMN funcional permite, em algumas situações, utilizando sequências de impulsos apropriadas, efectuar, com melhor regulação espacial do que a PET, estudos do caudal sanguíneo local, volume sanguíneo e oxigenação. Quando na RMN funcional a resposta não é possível, tal como na activação situacional única ou quando o movimento é um factor de perturbação, como no miocárdio e em tumores periféricos, a sensibilidade e especificidade da PET tornam-na o método indicado. 
Usando técnicas de PET, M. Raichle e os seus colegas da Universidade de Washington decobriram, em 1985, que a antecipação de um choque eléctrico activa a circulação sanguínea em ambos os lóbulos temporais. Depois dos estudos quantitativos da activação regional cerebral, realizados com a PET na década de 80 , baseados na medida do caudal sanguíneo usando água marcada com ${ }^{15} \mathrm{O}$, há razões para se acreditar que a medicina nuclear pode ajudar a fechar o círculo entre comportamento e bioquímica cerebral. Com uma focagem sobretudo na imagiologia molecular, parece existir campo de convergência da PET com as áreas de investigação mais importantes da medicina molecular. Embora a PET permita a identificação de estruturas moleculares específicas, associadas aos processos funcionais, os defeitos funcionais detectados exigem posterior estudo bioquímico e histoquímico.

Apesar do óbvio interesse deste método, e de se tratar praticamente do único que com alguma generalidade permite determinar as relações entre comportamento e bioquímica cerebral, o número de referências nas quais os estudos funcionais de PET são utilizados para obter informação sobre o stress é relativamente escasso.

Considerando a posição da PET no espectro da imagem médica, é de esperar que venha a ter uma utilização intensa e um longo futuro no estudo de receptores, neurotransmissores, ligação de drogas e farmacologia geral. Complementarmente, torna-se claro que dispõe de capacidades únicas em bioquímica/metabolismo e fisiologia. No que diz respeito à investigação, há que dar relevo ao uso da PET no sentido de obter novas informações nos processos associados às doenças com a finalidade de avaliar a eficiência dos mecanismos de terapêutica e apoiar a descoberta e desenvolvimento de novas drogas. A descoberta de informações novas sobre as doenças é a finalidade de muitos programas de investigação em neurociências, baseados na PET, com um interesse sempre crescente na área psiquiátrica.

Apesar da complexidade do tema, é notável observar como Alexandre Quintanilha consegue tornar de fácil compreensão para o não especialista alguns dos assuntos que aqui aflorei. 
 \\ A palavra "fronteiras" pode ser tomada em} diferentes sentidos. Pode referir-se aos limites, necessariamente provisórios, entre o conhecido e o desconhecido, ou aos limites entre o possivel e o impossivel, e, dentro do possivel, entre o desejável e 0 indesejável. Fronteiras podem também ser as delimitações, nem sempre nítidas, entre ciência e não-ciência, e dentro da ciência, entre as várias disciplinas. Quais são então as fronteiras da ciência?

Neste livro, a resposta a esta pergunta é dada, segundo as mais diferentes perspectivas, por um conjunto notável de personalidades, cientistas ou não, entre as quais se contam três Prémios Nobel.

Rui Fausto, Carlos fiolhais e JoÃo Fillipe Queiró são, respectivamente, professores de Química, Física e Matemática na Faculdade de Ciências e Tecnologia da Universidade de Coimbra. 